Research Article

\title{
Control of the Internal and External Staggered Distance of Coal Mining Face to the Water-Conducting Fissures in the Overlying Strata of the Near Coal
}

\author{
Zhiyuan Jin $\mathbb{D}^{1}$ and Tao Peng $\mathbb{D}^{1,2}$ \\ ${ }^{1}$ School of Mining Engineering, Guizhou Institute of Technology, Guiyang, Guizhou 550003, China \\ ${ }^{2}$ School of Resources \& Safety Engineering, Central South University, Changsha, Hunan 410083, China \\ Correspondence should be addressed to Tao Peng; pxt198712@126.com
}

Received 3 June 2021; Accepted 16 July 2021; Published 29 July 2021

Academic Editor: Dezhong Kong

Copyright (c) 2021 Zhiyuan Jin and Tao Peng. This is an open access article distributed under the Creative Commons Attribution License, which permits unrestricted use, distribution, and reproduction in any medium, provided the original work is properly cited.

In Northwest China, rainfall is low, water resources are scarce, and the ecological environment is fragile. For shallow-buried and close-spaced coal seams with a thickness of upper coal bed $>60 \sim 70 \mathrm{~m}$, the water-conducting fissures of the overlying rock will not penetrate the water-isolating layer after the upper coal seam is mined; the internal and external gap angles of the water-conducting fissures are not generated from the water-isolating layer. We set out to explore the critical internal and external dislocations for the second significant development of water-conducting fissures in the overlying rock after coal mining under control. A calculation model for the critical internal and external staggered distances of coal mining face in shallow-buried and close-spaced coal seams is established, the calculation formula is given, and the calculation formula for the critical seam mining ratio under the condition of internal staggered mining mode is given. Numerical simulation performed by UDEC methods: taking the overburden strata in the shallow-buried and close-spaced coal seam mining area of Shigetai Coal Mine as a prototype, it was verified that the critical internal and external offsets of the coal mining face in shallow-buried and close-spaced coal seams have a significant effect on the overlying water flow cracks in the mining of the lower coal seam. For the feasibility of developmental control, according to the engineering geological conditions of Shigetai, through the calculation method of external staggered distance, it is concluded that the distance of the open cut of the lower coal face and the upper coal face is only $21 \sim 27 \mathrm{~m}$, which is much smaller than the water barrier. It does not produce the critical distance of the water-conducting cracks. Therefore, in the process of mining the lower coal seam, the water-proof layer will produce water-conducting cracks, lose its water-proof performance, and cause water loss. This is also the cause of the water inrush accident in Shigetai Coal Mine.

\section{Introduction}

Taking the geological parameters that affect the development of water-conducting fissures in the overlying rock as the basic conditions, starting with the mining parameters, find the control methods. There is a soft rock water barrier in the shallow-buried and close-spaced Shendong coal mining area. Once the water barrier is stretched and damaged and eventually water-conducting cracks are formed, water resources will be lost. Looking for a control method for the development of water-conducting fissures in the overlying rock in the repeated disturbance zone is to find a control method that does not produce water-conducting fissures in the water barrier [1-6].

For the first type of shallow-buried and close-spaced coal seams in Northwest China (the thickness of the upper seam's bedrock $<50-60 \mathrm{~m}$ ), when the full-thickness long-wall mining method is adopted to mine the coal seam, the overburden water-conducting fissures will penetrate the ground surface, causing water resource loss. For such shallow-buried and close-spaced coal seams, even if the fullmining and full-filling coal mining method is adopted in the mining of the lower coal seam, the loss of water resources cannot be prevented, unless the overburden water- 
conducting fissures are grouted and blocked. For the second type of shallow-buried and close-spaced coal seams (the thickness of the upper seam's bedrock $>60 \sim 70 \mathrm{~m}$ ), when the full-thickness long-wall mining method is adopted to mine the coal seam, after the upper coal seam is mined, due to the expansion of the water-resistant layer existence, the waterconducting cracks in the overlying rock will not penetrate the water-impermeable layer in the end. When mining the lower coal seam, whether the water-conducting cracks in the overlying rock will penetrate the water-resistant layer is mainly related to the control method adopted. Therefore, exploring the control methods for the development of watertransmitting fissures in the overlying rock in shallow-buried and close-spaced coal seams will be carried out for the second type of shallow-buried and close-spaced coal seams.

Starting from the mining layout (the inner and outer staggered layouts of the mining face of the upper and lower coal seams), the effective way to is find the second significant development of the overlying water-conducting fissures in the smallest area after the mining of the lower coal seam.

\section{The Critical Inner and Outer Distances of the Water Barrier That Do Not Produce Water- Conducting Cracks}

Coal mining will cause overlying strata to move. Under sufficient mining conditions, the surface above the minedout area will sink to form a sinking basin. In the main section of the surface subsidence basin, the angle between the line from the edge point to the boundary point of the corresponding mined-out area and the horizontal line is called the strata movement boundary angle. The center of the sinking basin is a flat, no-deformation zone, and the angle between the line from the edge point to the boundary point of the corresponding mined-out area and the horizontal line is called the full-mining angle of rock formation. For shallowburied and close-spaced coal seams, the boundary angles and full-mining angles of the upper and lower coal seams during mining can be used to determine the critical inner and outer displacements of the aquifer without water-conducting cracks.

2.1. Internal Staggered Layout. When the upper and lower coal mining face adopts the internal staggered layout, if the development of the overlying water-conducting fissures near the upper coal seam's mining boundary can be maintained at the original stable state and no longer continue to develop after the lower coal seam is mined, then this type of internal error distance under the conditions is the critical internal error distance. After the coal seam is mined, the overlying rock layer is broken, forming a rock layer breaking line. The angle between the rock fracture line and the horizontal line is the rock fracture angle, generally $60-78^{\circ}$. The fracture angle of the rock formation is often greater than the full-mining angle of the rock formation movement [7].

When adopting the internal staggered layout, if the moving edge point of the water barrier (the intersection of the boundary line of the rock formation and the top surface of the water barrier) during the mining of the lower coal seam is located in the no-deformation zone of the sinking basin of the water barrier after the mining of the upper coal seam, then, during the mining process of the lower coal seam, the secondary development of water-conducting fissures in the overlying rock on the side of the cut-off cut in the upper coal seam will not occur. When mining shallowburied and close-spaced coal seams, the critical internal staggered layout of the upper and lower coal mining faces is shown in Figure 1.

According to the calculation model of the critical internal offset of the coal mining face in shallow-buried and close-spaced coal seams (as shown in Figure 2), the calculation formula of the critical internal offset $L_{\ln c}$ is

$$
L_{\ln c}=\left(h_{x f}-w_{s g}\right) \cot \psi_{s}+\left(h_{x f}+h_{c j}-w_{s g}\right) \cot \delta_{x},
$$

where $h_{x f}$ is the total thickness of the rock above the upper coal seam and below the aquifer, $m ; \psi_{s}$ is the full-mining angle after the upper coal seam is mined; $\delta_{x}$ is stratum movement boundary angle after mining of the lower coal seam; $w_{s g}$ is the maximum subsidence value of the aquifer when the upper coal seam is mined, $m ; h_{c j}$ is the thickness of interbedded rock in shallow-buried and close-spaced coal seams, $m$.

2.2. External Staggered Distance $L_{l w c}$. Figure 3 shows the overall external staggered layout of the coal face under the shallow-buried and close-spaced coal seam. When the shallow-buried and short-distance coal seam adopts the external staggered layout, if the boundary point of the nodeformation zone of the sinking basin of the lower coal seam is located at the boundary point of the water-resisting layer movement during the mining of the upper coal seam (the boundary line of the rock layer movement and the water barrier except for the intersection point of the top surface of the seam), the mining of the lower coal seam will not cause the secondary development of water-conducting fissures in the upper coal seam on the side of the cut.

The calculation model of the critical distance for shallow-buried and close-spaced coal seams is shown in Figure 4. The calculation formula for the critical distance is as follows:

$$
L_{l w c}=\left(h_{c j}+M_{s}+h_{x f}\right) \cot \psi_{x}+h_{x f} \cot \delta_{s}
$$

where $h_{c j}$ is the thickness of interlayer rock, $m ; M_{s}$ is the upper seam's thickness, $m$; $\psi_{x}$ is the full-mining angle when mining the lower coal seam; and $\delta_{s}$ is stratum movement boundary angle during upper coal mining.

The seam mining ratio is proposed for the mining of close-spaced coal seams, and its meaning is the ratio of the thickness of the interlayer rock layer to the mining height of the lower coal seam, $\eta$; that is, $\eta=h_{c j} / M_{x}$.

When the external staggered layout is adopted, the development of water-transmitting fissures in the overlying rock during the mining process of the shallow-buried and close-spaced coal seam can be regarded as a single coal seam (lower coal seam) mining for research. In some cases, due to the restriction of the production geological conditions, the 


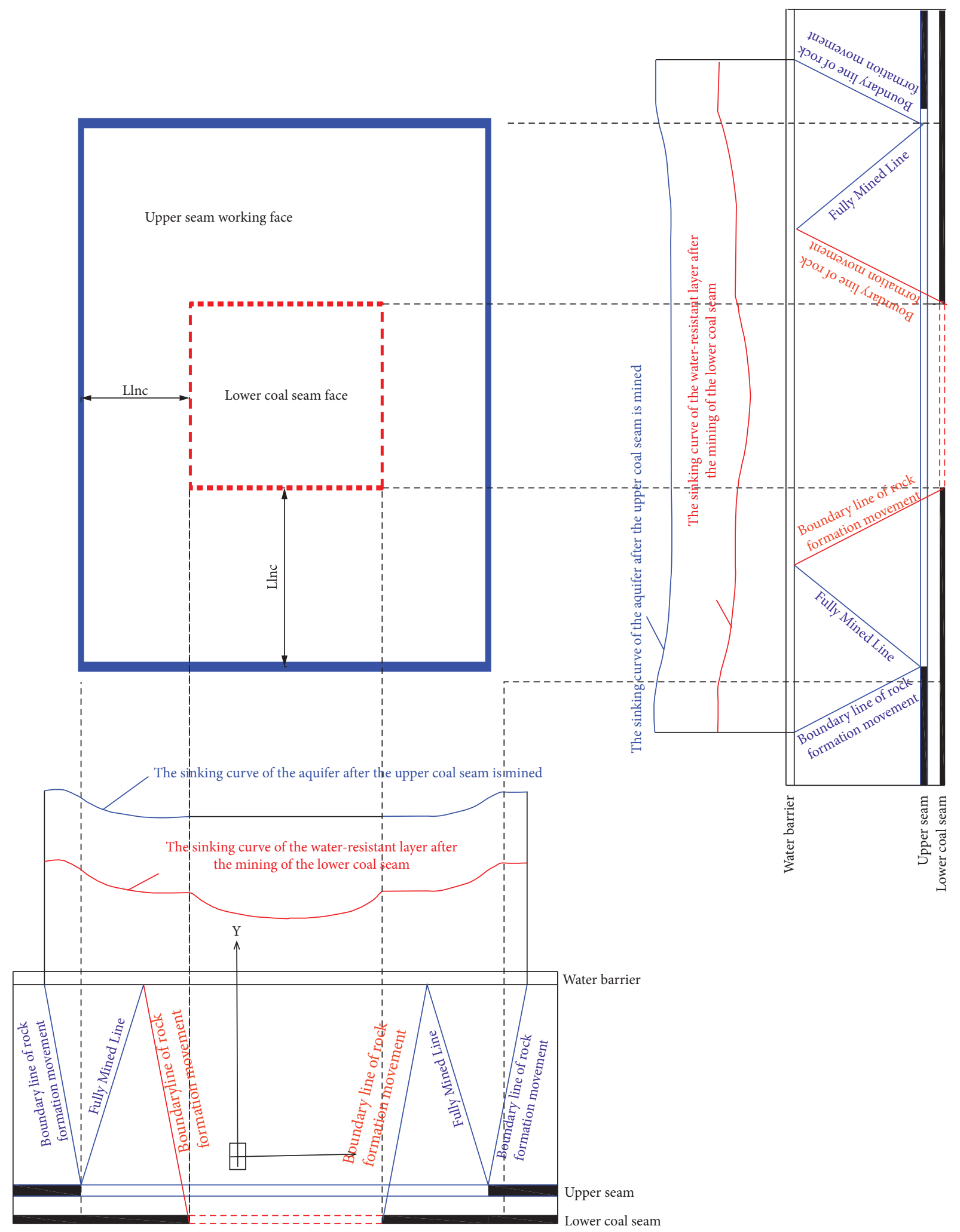

Figure 1: Internal displacement of the whole working face in the lower coal seam of shallow-buried short-distance coal seams.

internal staggered layout is required. Then, it is necessary to study the critical stratum mining ratio that does not produce water-conducting cracks in the water barrier.
2.2.1. The Minimum Value of the Maximum Subsidence Value When the Water Barrier Does Not Produce WaterConducting Cracks. According to existing research results, 


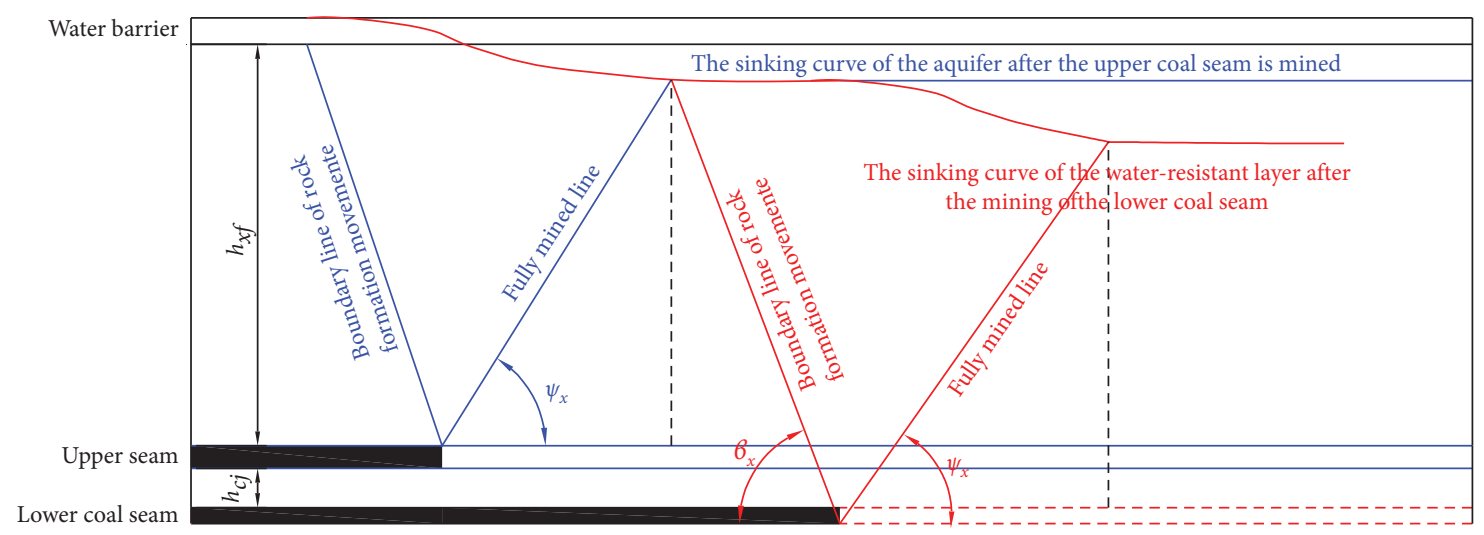

FIGURE 2: Calculating model of internal dislocation of the whole working face in the lower coal seam of shallow-buried short-distance coal seams.

the relationship between the crack width of the aquifer and its maximum subsidence value is

$$
d=0.9273 \ln w+0.7463
$$

where $d$ is the water barrier crack width; $w$ is the maximum subsidence value when the water barrier does not produce water-conducting cracks.

The nonhydrophilic water barrier material measured by the lateral restraint expansion experiment is $L_{p z}=0.605 \mathrm{~mm}$. To ensure that water resources are not lost, $d_{\mathrm{d} x} \geq 0$; that is, $d>2 L_{p z}=1.210 \mathrm{~mm}$. Substituting formula (3), we have $w_{l j} \leq 1.649 \mathrm{~m}$.

Therefore, $w_{l j}=1.649 \mathrm{~m}$ is the minimum maximum subsidence value when the water barrier does not produce water-conducting cracks. When it is $w_{l j}>1.649 \mathrm{~m}$, waterconducting fissures will occur in the water barrier.

\subsubsection{Critical Layer Mining Ratio Where the Water Barrier} Does Not Produce Water-Conducting Cracks $\eta_{l j}$. Shallow-buried and close-spaced coal seams adopt internal staggered arrangement. When the internal staggered distance is greater than the critical inner staggered distance, the area where the overlying strata moved and the cracks developed due to the mining of the lower coal seam is located in the no-deformation zone of the sinking basin after the upper coal seam is mined; that is to say, before the mining of the lower coal seam, the rock layers in the repeated disturbance zone were in a horizontal state. The hard rock layers were broken into blocks and squeezed and closed horizontally, while the soft rock water barrier did not undergo horizontal tensile deformation and did not produce water-conducting cracks.

Whether there are water-conducting cracks in the water barrier is mainly related to the height of the effective sinking space below, in addition to its physical and mechanical properties and hydraulic properties. The factors that determine the height of the effective sinking space are the thickness of the underlying rock layer and its residual swelling coefficient. According to existing research results, for close-spaced coal seams, after the lower coal seam is mined, the residual breaking expansion coefficient of the rock strata in the upper coal seam mining caving zone will become smaller, but the magnitude is not large, and the rock strata in the upper coal seam mining fracture zone will enter the caving zone, and the residual breaking expansion coefficient will increase, but the amplitude is not very large. On the whole, after the lower coal seam is mined, the residual breaking expansion coefficient of the overlying rock of the upper coal seam can be regarded as unchanged, and the shallow-buried and close-spaced coal seams also conform to this law. Therefore, for shallow-buried and close-spaced coal seams, when the internal fault distance is greater than the critical internal fault distance, the lower coal seam can be regarded as a single coal seam mining, and the thickness of the overlying rock layer is the layer spacing. Under the condition of the internal staggered arrangement, the critical condition for the water barrier not to produce water-conducting cracks is

$$
w_{l j} \geq M_{x}-h_{c j} \cdot\left(\overline{k_{c c}}-1\right)=M_{x}\left(1-\eta_{l j} \cdot\left(\overline{k_{c c}}-1\right)\right),
$$

where $\overline{k_{c c}}$ is the average residual breaking expansion coefficient of the interlayer rock formation.

It is concluded that the critical layer mining ratio for the water barrier without water-conducting cracks is

$$
\eta_{l j}=\frac{M_{x}-w_{l j}}{M_{x} \cdot\left(\overline{k_{c c}}-1\right)} \text {. }
$$

At the same time, according to formulas (5) and (6), it can also be determined that the reasonable mining height of the lower coal seam when the water-resistant layer does not produce water-conducting cracks is

$$
M_{h x} \leq w_{l j}+h_{c j} \cdot\left(\overline{k_{c c}}-1\right) .
$$

\section{Numerical Simulation Analysis}

Taking the overburden strata in the shallow-buried and close-spaced coal mining area of Shigetai Coal Mine as a prototype, the overburden parameters are shown in Table 1 [8-11].

Using UDEC's stress-seepage coupling system, simulation calculation, and analysis of the development law and seepage characteristics of the internal and external 


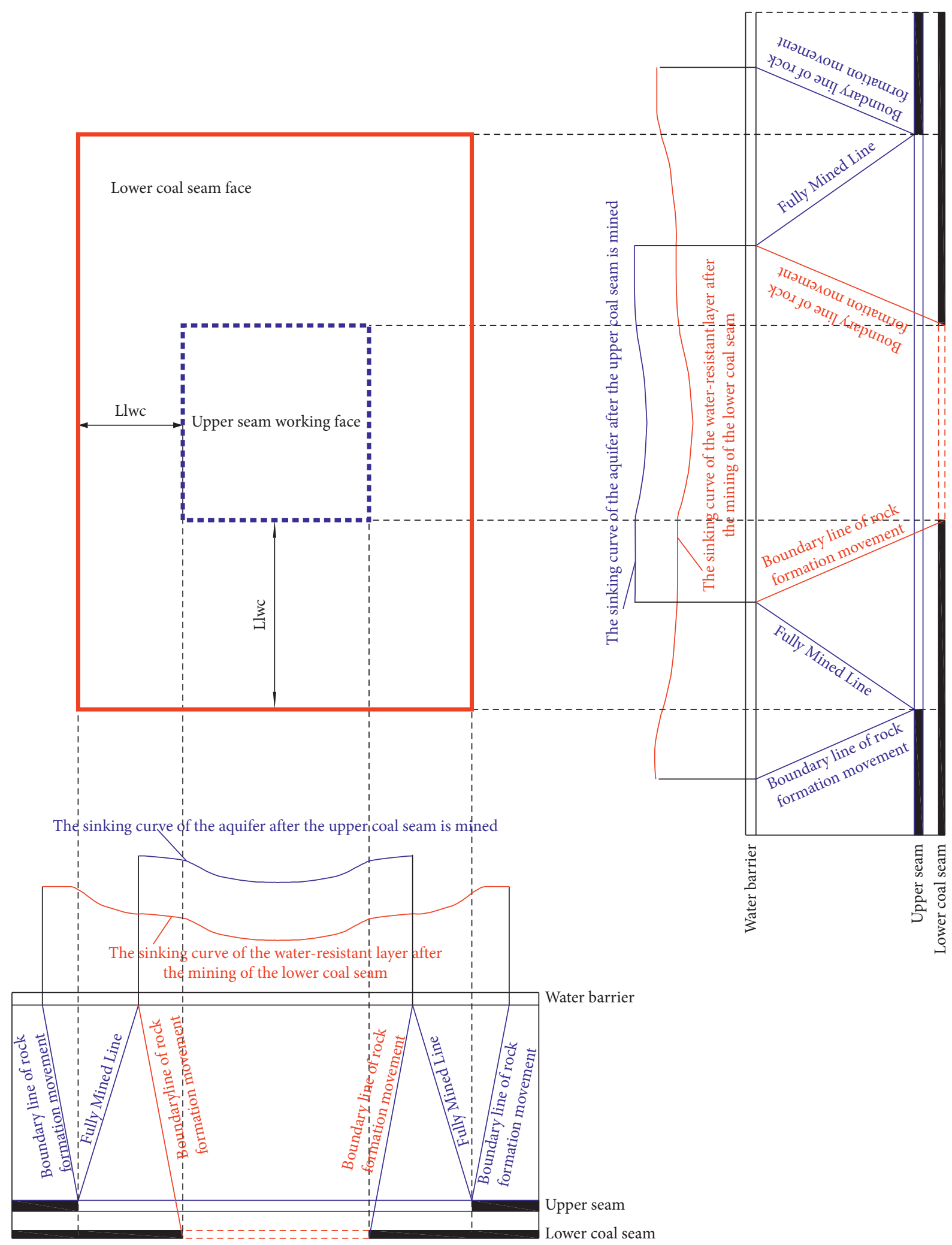

FIGURE 3: Outward displacement of the whole working face in the lower coal seam of shallow-buried short-distance coal seams.

offsets to the overburden seepage fissures during the mining of shallow-buried and close-spaced coal seams, according to the measured physical and mechanical parameters of the overburden, the model parameters are assigned. The rock mechanical parameters are shown in Table 2, and the rock joint parameters are shown in Table 3 . The boundary conditions are as follows: the left and right sides and the lower part of the model are 


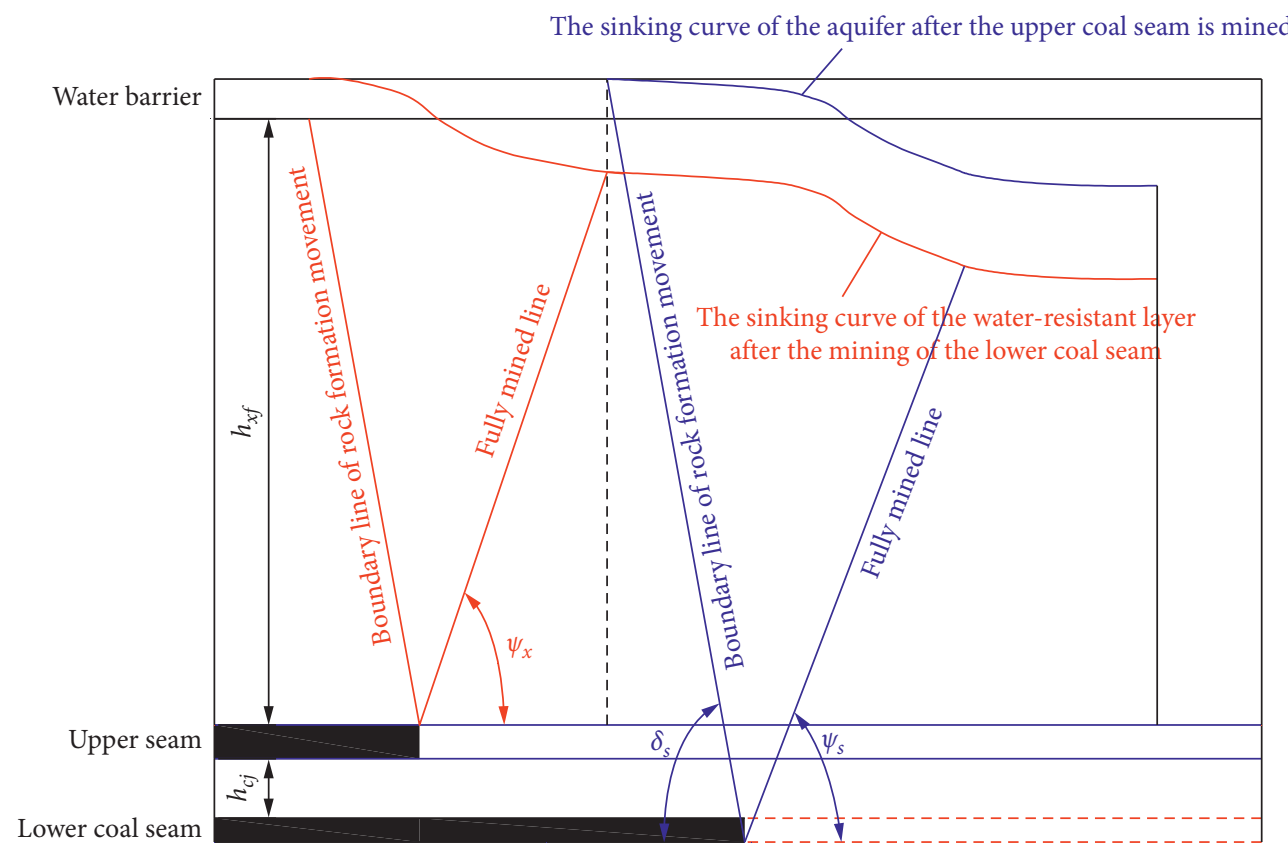

FIGURE 4: The calculation model of outward dislocation of the whole working face in the lower coal seam of shallow-buried short-distance coal seams.

TABLE 1: The overburden parameters.

\begin{tabular}{|c|c|c|c|}
\hline Serial number & Lithology & Thickness & Remarks \\
\hline 1 & Loose layer & 5 & \\
\hline 2 & Loess & 6 & Water barrier \\
\hline 3 & Sandy mudstone & 6 & \\
\hline 4 & Silt sandstone & 7 & \\
\hline 5 & Medium-grained sandstone & 3 & \\
\hline 6 & Fine-grained sandstone & 16 & Thick hard rock \\
\hline 7 & Sandy mudstone & 6 & \\
\hline 8 & Medium-grained sandstone & 9 & \\
\hline 9 & Silt sandstone & 7 & \\
\hline 10 & Coarse-grained sandstone & 3 & \\
\hline 11 & Medium-grained sandstone & 10 & Basic top \\
\hline 12 & Sandy mudstone & 5 & \\
\hline 13 & Upper seam & 2.5 & \\
\hline 14 & Silt sandstone & 7 & \\
\hline 15 & Medium-grained sandstone & 14 & \\
\hline 16 & Coarse-grained sandstone & 10 & \\
\hline 17 & Lower coal seam & 3 & \\
\hline 18 & Fine-grained sandstone & 5 & \\
\hline
\end{tabular}

displacement boundaries and nonseepage boundaries. The simulated solid-liquid coupling adopts SET steady flow, and the joint characteristics adopt the default setting (the second type). The initial pore pressure is set as $\mathrm{pp}=0.125 \mathrm{MPa}$.

3.1. The Influence of Internal Staggered Distance on the Water-Conducting Fissures. Numerical models of different internal error distances are established, and the simulation results are shown in Figure 5.
From the analysis of Figure 5, it can be seen that, with the increase of the internal staggered distance, the secondary development degree of the water-conducting fissures on the side of the cut-off cut in the upper coal seam gradually decreases. When the internal staggered distance is less than $80 \mathrm{~m}$, the mining of the lower coal seam will cause the waterconducting fissures on the side of the open cut to develop twice; when the internal staggered distance is $80 \mathrm{~m}$, the water-conducting fissures on the side of the open cut will not be affected by the mining of the lower coal seam. Without secondary development, it can maintain the original stable 
TABLE 2: The mechanical parameters of rock.

\begin{tabular}{|c|c|c|c|c|c|c|}
\hline Rock formation & $\begin{array}{l}\text { Density } d \\
\left(\mathrm{~kg} \cdot \mathrm{m}^{-3}\right)\end{array}$ & $\begin{array}{l}\text { Bulk modulus } k \\
(\mathrm{GPa})\end{array}$ & $\begin{array}{c}\text { Shear modulus } g \\
(\mathrm{MPa})\end{array}$ & $\begin{array}{c}\text { Cohesion } c \\
(\mathrm{MPa})\end{array}$ & $\begin{array}{c}\text { Internal friction } \\
\text { angle } f\left({ }^{\circ}\right)\end{array}$ & $\begin{array}{l}\text { Tensile strength } \sigma_{\mathrm{t}} \\
(\mathrm{MPa})\end{array}$ \\
\hline Coal seam & 1400 & 2.3 & 2 & 1.25 & 27 & 0.6 \\
\hline Silt sandstone & 2420 & 30.3 & 13 & 9.6 & 33 & 6 \\
\hline $\begin{array}{l}\text { Coarse-grained } \\
\text { sandstone }\end{array}$ & 2480 & 19 & 12.1 & 4.3 & 32 & 6 \\
\hline $\begin{array}{l}\text { Medium-grained } \\
\text { sandstone }\end{array}$ & 2500 & 37.5 & 19.5 & 4.3 & 33 & 3.2 \\
\hline $\begin{array}{l}\text { Fine-grained } \\
\text { sandstone }\end{array}$ & 2510 & 40.8 & 20.2 & 4.3 & 33 & 3.2 \\
\hline Sandy mudstone & 2410 & 6.3 & 6.9 & 6.7 & 31.5 & 2 \\
\hline Loess & 1720 & 20 & 14.2 & 3 & 15 & 4.3 \\
\hline Loose layer & 2200 & 14 & 11.5 & 10 & 32 & 2 \\
\hline
\end{tabular}

TABLE 3: The mechanical parameters of the rock joints.

\begin{tabular}{|c|c|c|c|c|c|c|}
\hline Rock formation & $\begin{array}{c}\text { Normal stiffness } \\
(\mathrm{MPa})\end{array}$ & $\begin{array}{l}\text { Tangential stiffness } \\
(\mathrm{MPa})\end{array}$ & $\begin{array}{c}\text { Cohesion } \\
(\mathrm{MPa})\end{array}$ & $\begin{array}{l}\text { Joint penetration factor } \\
\left(\mathrm{Pa}^{-1} \cdot \mathrm{s}^{-1}\right)\end{array}$ & $\begin{array}{l}\text { Initial gap } \\
(\mathrm{mm})\end{array}$ & $\begin{array}{l}\text { Residual gap } \\
(\mathrm{mm})\end{array}$ \\
\hline Coal seam & 1600 & 1100 & 0.313 & 166.7 & 0.5 & 0.1 \\
\hline Silt sandstone & 7600 & 5200 & 0.800 & 166.7 & 0.5 & 0.1 \\
\hline $\begin{array}{l}\text { Coarse-grained } \\
\text { sandstone }\end{array}$ & 7900 & 5600 & 0.688 & 166.7 & 0.5 & 0.1 \\
\hline $\begin{array}{l}\text { Medium-grained } \\
\text { sandstone }\end{array}$ & 7500 & 5500 & 0.712 & 166.7 & 0.5 & 0.1 \\
\hline $\begin{array}{l}\text { Fine-grained } \\
\text { sandstone }\end{array}$ & 8800 & 6600 & 0.690 & 166.7 & 0.5 & 0.1 \\
\hline Sandy mudstone & 6400 & 4500 & 0.375 & 101.5 & 0.5 & 0.1 \\
\hline Loess & 9000 & 7900 & 0.311 & 15 & 0.1 & 0.1 \\
\hline Loose layer & 2200 & 1300 & 0.100 & 300 & 3.0 & 0.1 \\
\hline
\end{tabular}

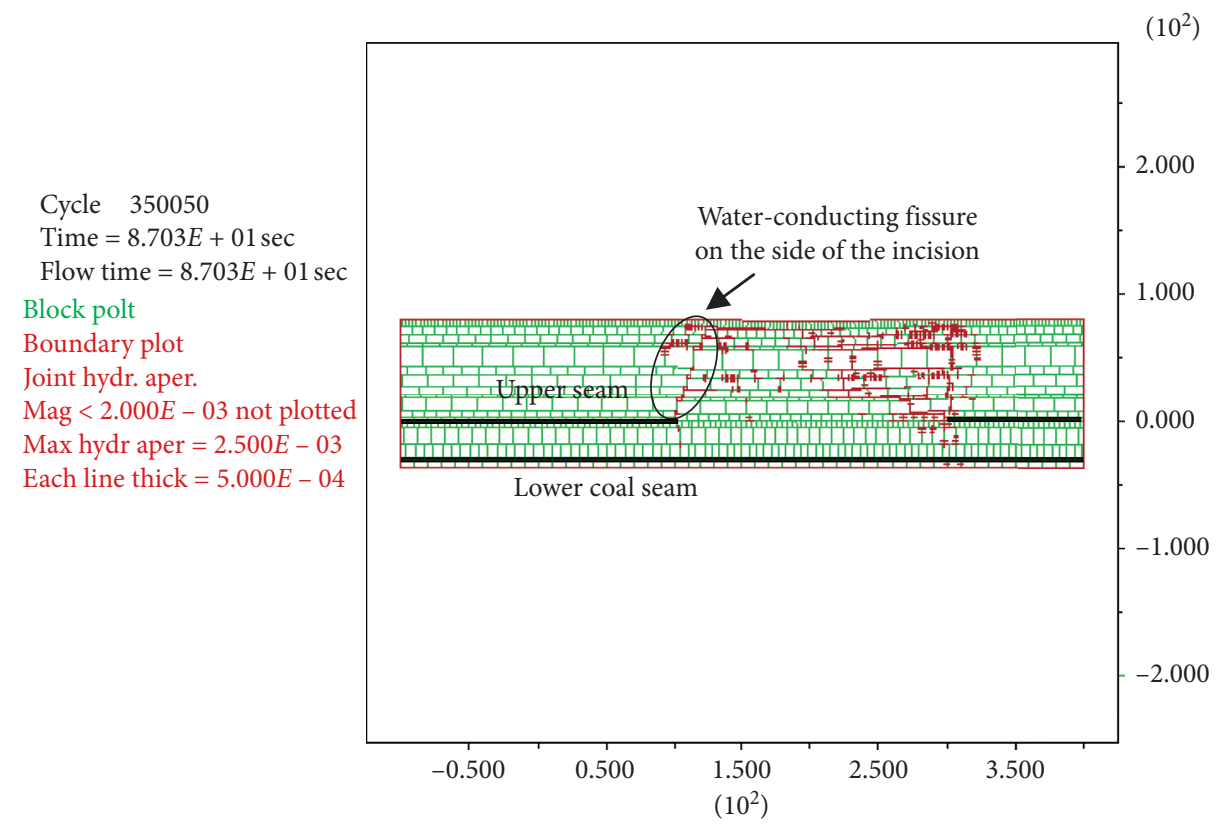

(a)

Figure 5: Continued. 


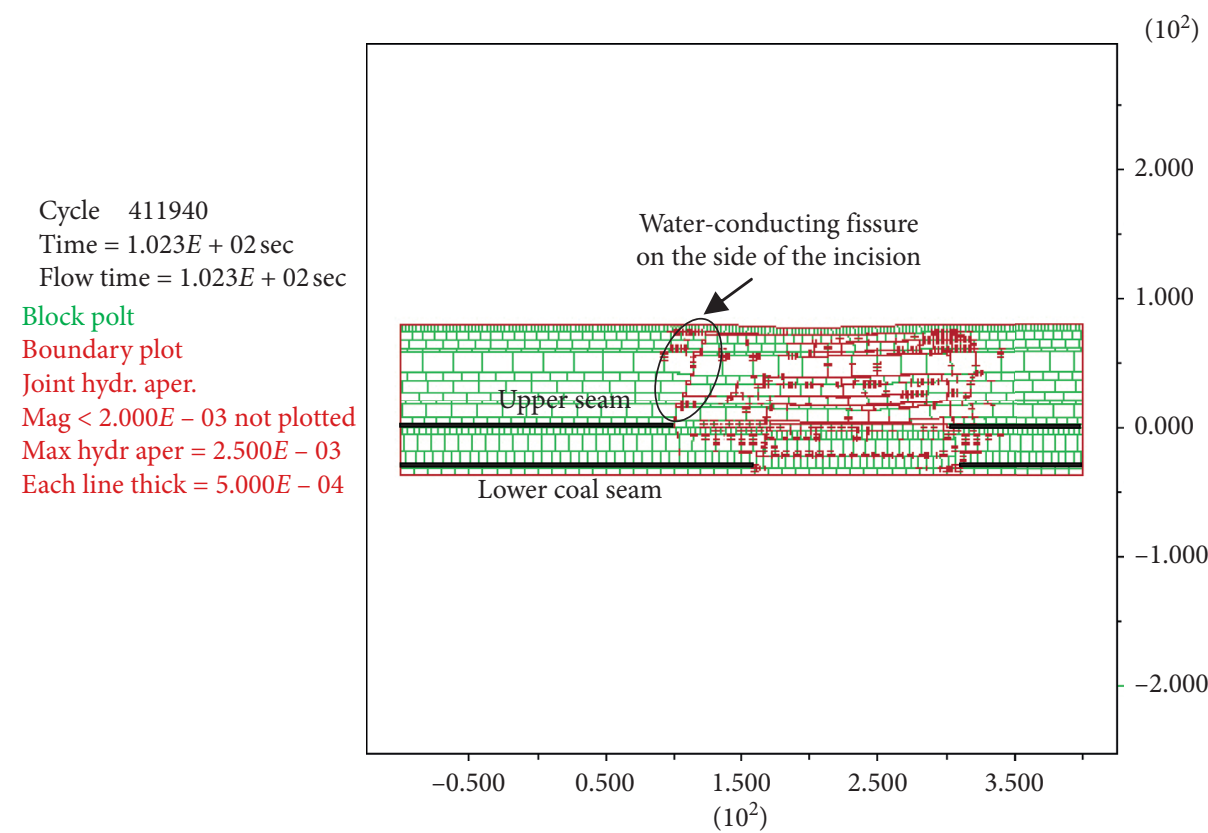

(b)

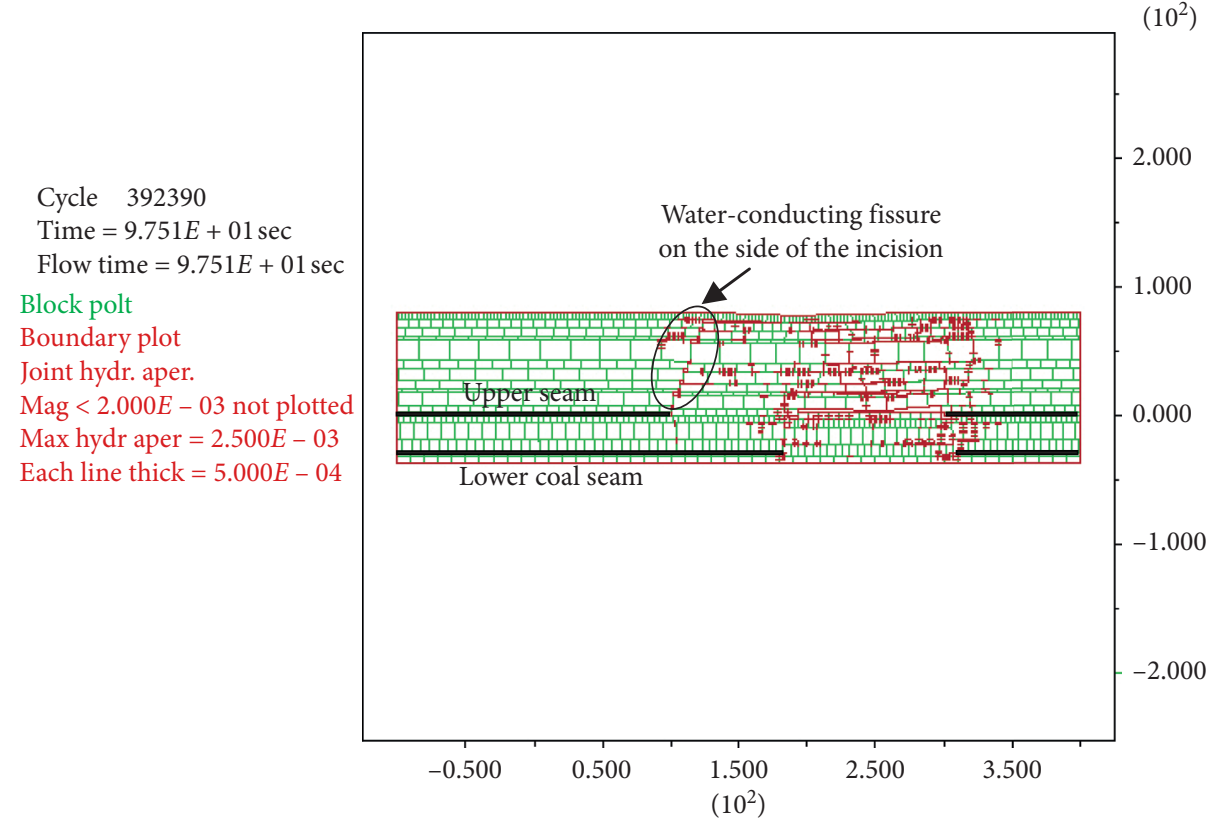

(c)

FIGURE 5: Water flowing fractures development characteristics of overburden rock with the different internal dislocation of shallow-buried short-distance coal seams. (a) After the upper seam is mined. (b) Internal staggered distance of $60 \mathrm{~m}$. (c) Internal staggered distance of $80 \mathrm{~m}$.

state after the upper coal seam is mined (before the lower coal seam is mined).

3.2. The Influence of External Staggered Distance on the Water-Conducting Fissures of the Overlying Rock. Numerical models of different external error distances are established, and the simulation results are shown in Figure 6.

It can be seen from the analysis of Figure 6 that, with the increase of the external staggered distance, the development degree of the overlying rock water-conducting fissures on the side of the cut-off cut in the upper coal seam gradually decreases. When the offset distance is less than $80 \mathrm{~m}$, the mining of the lower coal seam will cause the secondary development of the water-conducting fissures on the open cut side of the upper coal seam; and when the external staggered distance is greater than $90 \mathrm{~m}$, the water-conducting fissures on the open cut side of the upper coal seam will not develop. Affected by the mining of the lower coal seam, new water-conducting fissures are generated in the 
Cycle 350050

Time $=8.703 E+01 \mathrm{sec}$

Flow time $=8.703 E+01 \mathrm{sec}$

Block polt

Boundary plot

Joint hydr. aper.

Mag $<2.000 E-03$ not plotted

Max hydr aper $=2.500 E-03$

Each line thick $=5.000 E-04$

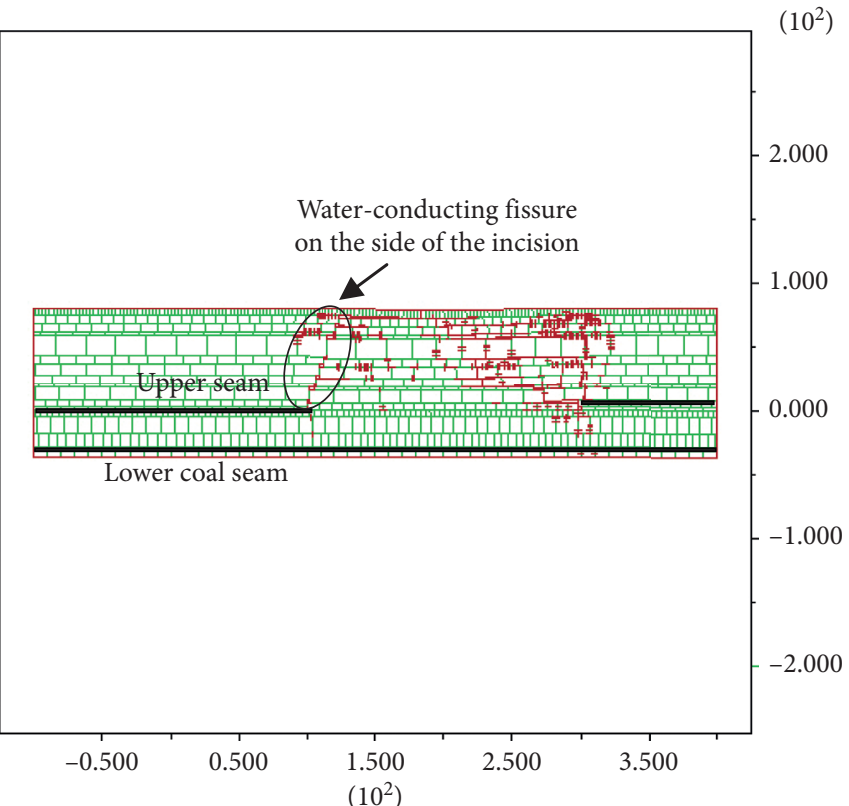

(a)

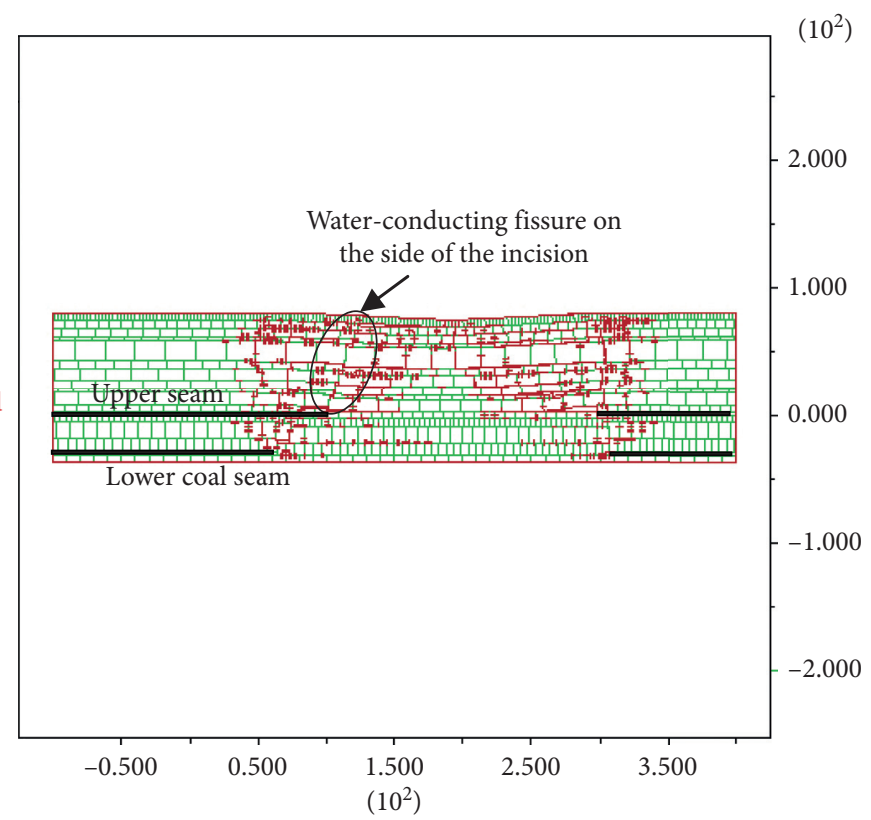

(b) $\left.0^{2}\right)$

.000

000

000

.000

000

$\left.10^{2}\right)$

000

000

000

.000

2.000
Cycle 419391

Time $=1.042 E+02 \mathrm{sec}$

Flow time $=1.042 E+02 \mathrm{sec}$

Block polt

Boundary plot

Joint hydr. aper.

Mag $<2.000 E-03$ not plotted

Max hydr aper $=2.500 E-03$

Each line thick $=5.000 E-04$

Figure 6: Continued. 


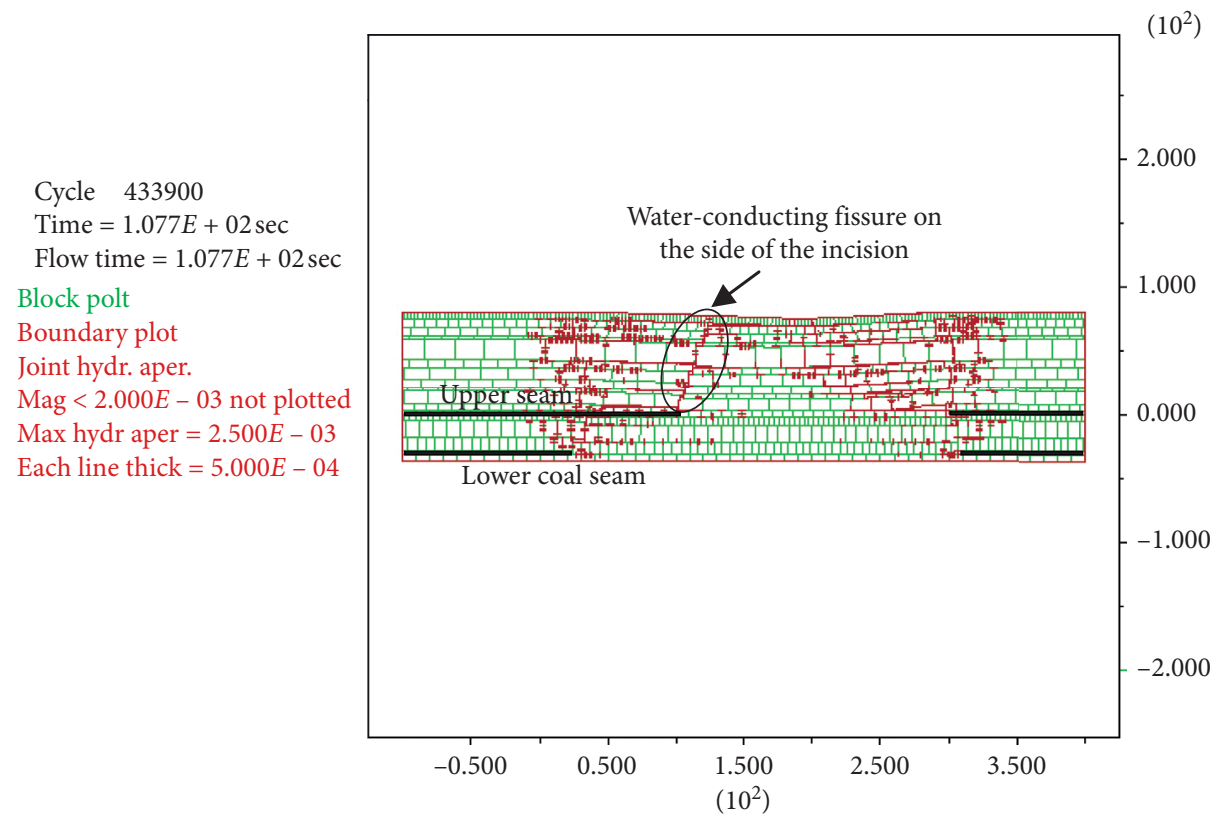

(c)

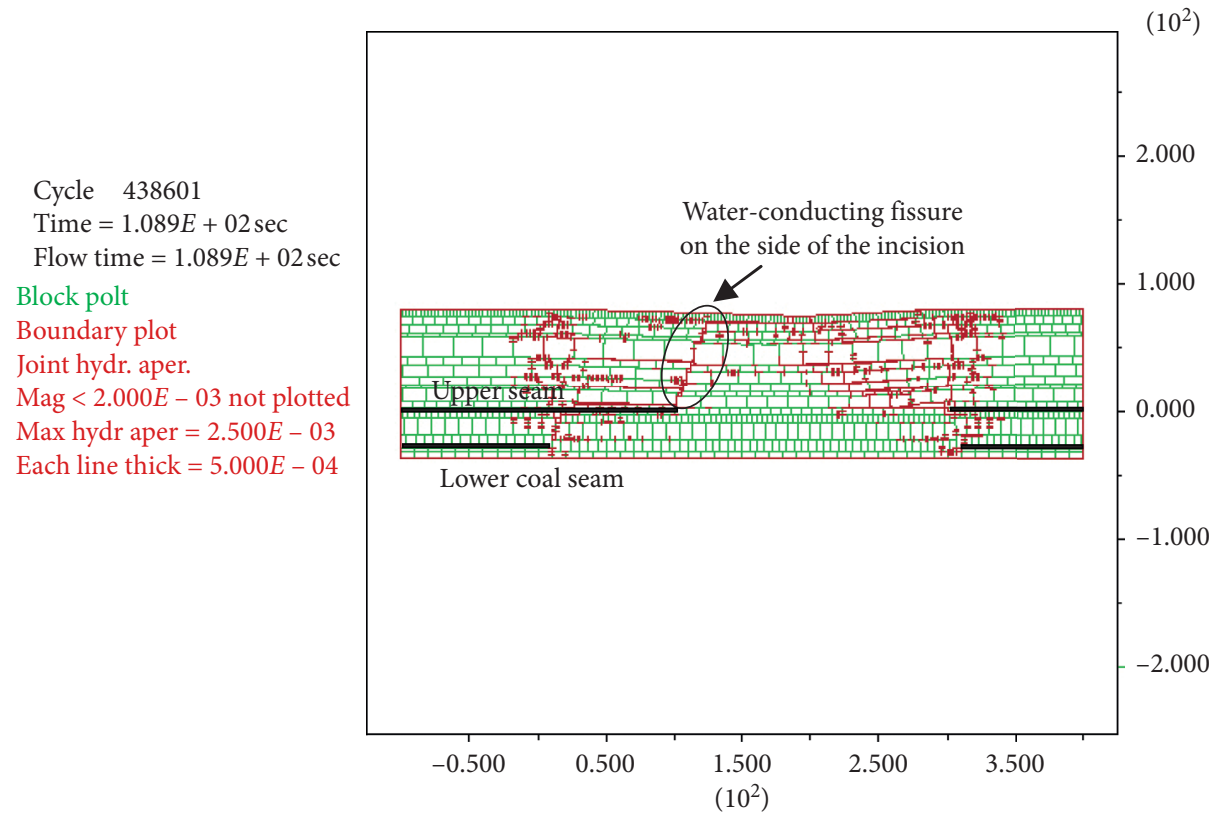

(d)

FIGURE 6: Water flowing fractures development characteristics of overburden rock with the different outward dislocation of shallow-buried short-distance coal seams. (a) After the upper seam is mined. (b) External staggered distance of $40 \mathrm{~m}$. (c) External staggered distance of $80 \mathrm{~m}$. (d) External staggered distance of $90 \mathrm{~m}$.

overlying rock near the mining boundary of the lower coal seam.

\section{Reverse Verification of Project Examples}

At 5:50 in the morning on August 2, 2010, the head of the lower coal seam was advanced by $17.5 \mathrm{~m}$ and the tail was advanced by $21.5 \mathrm{~m}$. A roof water gushing accident occurred. The total amount of water gushing was about $47,000 \mathrm{~m}^{3}$, causing the equipment in the fully mechanized mining face to be flooded. The location of the water gushing is shown in Figure 7, and the actual photo of the scene is shown in Figure 8 [12].

According to the geological conditions of the water gushing site in Shigetai Coal Mine, the distance between the upper coal seam and the lower coal seam is $2.6 \mathrm{~m}$, and the bedrock thickness of the upper coal seam is $76.37 \mathrm{~m}$. According to the calculation method of the critical external 


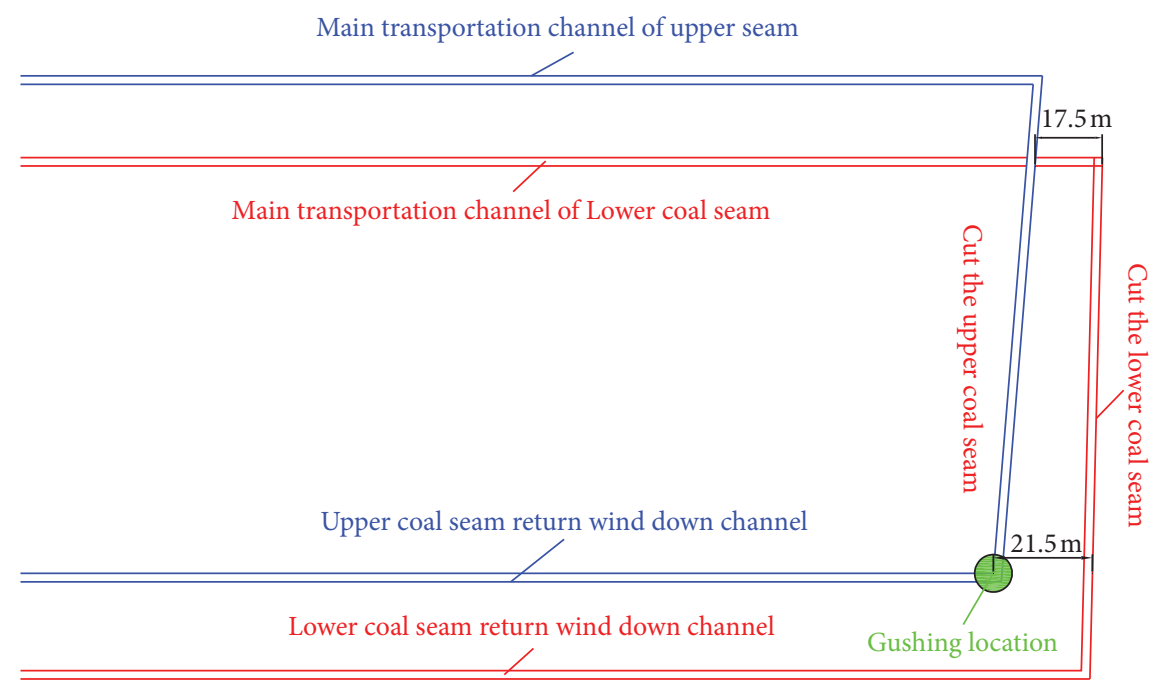

FIgURE 7: Water gushing position on upper coal seam face.

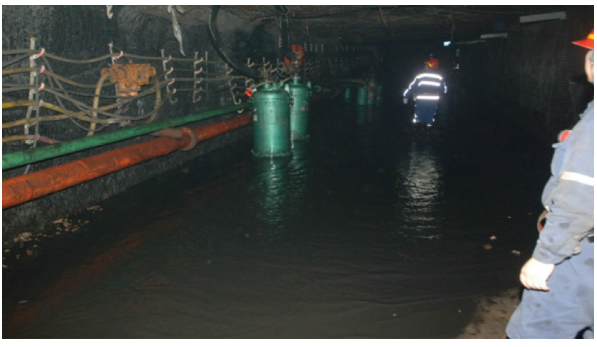

Figure 8: The actual photo of the scene.

offset, $\psi_{s}=60^{\circ}, \delta_{x}=73^{\circ}, h_{c j}=2.6 \mathrm{~m}, h_{x f}=76.37 \mathrm{~m}$, and $w_{s g}=0.86 \mathrm{~m}$, substituted into equations (1)-(6), and the calculation is $L_{\ln c}=68.12 \mathrm{~m}$. At the site of the roof water gushing accident, the distance between the lower seam face and the upper seam face is only $21 \sim 27 \mathrm{~m}$, which is far smaller than the critical outer staggered distance where the water barrier does not produce water-conducting cracks. Therefore, in the process of mining the lower coal seam, the waterproof layer will produce water-conducting cracks, lose the water-proof performance, and cause water loss.

\section{Conclusion}

(1) For the second type of shallow-buried and closespaced coal seams (the thickness of the base rock of the upper coal seam $>60 \sim 70 \mathrm{~m}$ ), under the conditions of repeated disturbance and multiple mining, the lower water-conducting cracks of the overburden water-proof layer are given. The calculation formula for the critical inner and outer staggered distances of the coal seam determines the calculation method for the critical stratum mining ratio that does not produce water-conducting cracks in the overburden water-resistant layer under the condition of inner staggered layout.

(2) The roof water gushing accident at the fully mechanized coal mining face of Shigetai Coal Mine's coal seam 12 caused the equipment in the working face to be flooded. The main reason was that the distance between the open cut of the lower coal face and the upper coal face was only $21 \sim 27 \mathrm{~m}$, which is smaller than the critical distance of the water barrier that does not produce water-conducting cracks.

\section{Data Availability}

The data used to support the findings of this study are included within the article.

\section{Conflicts of Interest}

The authors declare that they have no known conflicts of interest that could influence the work reported in this paper.

\section{Acknowledgments}

This paper was supported by Guizhou Province Basic Research (Science and Technology Fund) Project (Qiankehe Foundation [2020] 1Y215).

\section{References}

[1] Q. X. Huang, Research on Roof Structure and Strata Control of Longwall Mining in Shallow Coal Seam, China University of Mining and Technology Press, Xuzhou, China, 2000.

[2] Q. X. Huang, "Roof structure theory and support resistance determination longwall face in shallow seam," Journal of Coal Science and Engineering, vol. 29, pp. 21-24, 2003.

[3] S.S. Peng, Coal Mine Ground Control, Wiley-Inter Science Publication, New York, NY, USA, 1978.

[4] D. S. Zhang, G. W. Fan, L. Q. Ma, and X. F. Wang, "Aquifer protection during longwall mining of shallow coal seams: a case study in the Shendong coalfield of China," International Journal of Coal Geology, vol. 86, no. 2-3, pp. 190-196, 2011.

[5] D. Zhang, G. Fan, Y. Liu, and L. Ma, "Field trials of aquifer protection in longwall mining of shallow coal seams in China," International Journal of Rock Mechanics and Mining Sciences, vol. 47, no. 6, pp. 908-914, 2010. 
[6] L. Q. Ma and D. S. Zhang, Research on the Mechanism and Application of Water-Retaining Mining in Longwall Working Face in Shallow Coal Seam, China University of Mining and Technology Press, Xuzhou, China, 2012.

[7] G. Q. He, L. Yang, G. D. Ling et al., Mining Subsidence Science, China University of Mining and Technology Press, Xuzhou, China, 1991.

[8] Z. Y. Jin, The Development and Control of Water-Transmitting Fissures in the Overlying Rock in the Repetitively Disturbed Area of Shallow and Close Coal Seams, China University of Mining and Technology, Xuzhou, China, 2015.

[9] D. Z. Kong, S. J. Pu, Z. H. Cheng, G. Y. Wu, and Y. Liu, "Coordinated deformation mechanism of the top coal and filling body of gob-side entry retaining in a fully mechanized caving face," International Journal of Geomechanics, vol. 21, no. $4,2021$.

[10] D.-Z. Kong, Z.-B. Cheng, and S.-S. Zheng, "Study on the failure mechanism and stability control measures in a largecutting-height coal mining face with a deep-buried seam," Bulletin of Engineering Geology and the Environment, vol. 78, no. 8, pp. 6143-6157, 2019.

[11] J. F. Lou, F. Q. Gao, J. H. Yang et al., "Characteristics of evolution of mining-induced stress field in the longwall panel: insights from physical modeling," International Journal of Coal Science \& Technology, 2021.

[12] "Report on water inrush accident at 12105 working face of Shigetai Coal Mine," 2010, http://wenku.baidu.com/view/ 94b01ec6d5bbfd0a7956737e.html. 